OPEN ACCESS

Edited by:

Steve Perlman

University of Victoria, Canada

Reviewed by:

Takahiro Hosokawa

Kyushu University, Japan

Elad Chiel,

University of Haifa, Israel

*Correspondence:

Gregory D. D. Hurst

g.hurst@liverpool.ac.uk

tThese authors have contributed equally to this work

¥ORCID:

Panupong Thongprem orcid.org/0000-0001-6542-235X

Sophie E. F. Evison orcid.org/0000-0002-6210-533X

Gregory D. D. Hurs orcid.org/0000-0002-7163-7784

Oliver Otti

orcid.org/0000-0002-2361-9661

Specialty section:

This article was submitted to Microbial Symbioses,

a section of the journal

Frontiers in Microbiology

Received: 21 September 2020 Accepted: 30 November 2020 Published: 23 December 2020

Citation:

Thongprem P, Evison SEF, Hurst GDD and Otti $O$ (2020) Transmission, Tropism, and Biological Impacts of Torix Rickettsia in the Common Bed Bug Cimex lectularius (Hemiptera: Cimicidae).

Front. Microbiol. 11:608763. doi: 10.3389/fmicb.2020.608763

\section{Transmission, Tropism, and Biological Impacts of Torix Rickettsia in the Common Bed Bug Cimex lectularius (Hemiptera: Cimicidae)}

\author{
Panupong Thongprem ${ }^{1 \neq}$, Sophie E. F. Evison ${ }^{2 \neq}$, Gregory D. D. Hurst ${ }^{1 * t \neq}$ and Oliver Otti ${ }^{3+\ddagger}$ \\ ${ }^{1}$ Institute of Infection, Veterinary and Ecological Sciences, University of Liverpool, Liverpool, United Kingdom, ${ }^{2}$ Faculty of \\ Medicine \& Health Sciences, University Park, Nottingham, United Kingdom, ${ }^{3}$ Animal Population Ecology, Animal Ecology I, \\ Bayreuth Center for Ecology and Environmental Research (BayCEER), University of Bayreuth, Bayreuth, Germany
}

The torix group of Rickettsia have been recorded from a wide assemblage of invertebrates, but details of transmission and biological impacts on the host have rarely been established. The common bed bug (Cimex lectularius) is a hemipteran insect which lives as an obligatory hematophagous pest of humans and is host to a primary Wolbachia symbiont and two facultative symbionts, a BEV-like symbiont, and a torix group Rickettsia. In this study, we first note the presence of a single Rickettsia strain in multiple laboratory bed bug isolates derived from Europe and Africa. Importantly, we discovered that the Rickettsia has segregated in two laboratory strains, providing infected and uninfected isogenic lines for study. Crosses with these lines established transmission was purely maternal. Fluorescence in-situ hybridization analysis indicates Rickettsia infection in oocytes, bacteriomes, and other somatic tissues. We found no evidence that Rickettsia infection was associated with sex ratio distortion activity, but Rickettsia infected individuals developed from first instar to adult more slowly. The impact of Rickettsia on fecundity and fertility resulted in infected females producing fewer fertile eggs. However, we could not find any evidence for cytoplasmic incompatibility associated with Rickettsia presence. These data imply the existence of an unknown benefit to C. lectularius carrying Rickettsia that awaits further research.

Keywords: torix Rickettsia, Cimex lectularius, endosymbiont, maternal inheritance, symbiosis

\section{INTRODUCTION}

Symbioses between insects and bacteria are both common and important. Bacterial symbionts impact on the biology of their host individual, and also by extension affect the ecology and evolution of their host (Mitter et al., 1988; Sudakaran et al., 2017). Effects are diverse, with beneficial effects ranging from nutritional (e.g., anabolism or digestion), protection against multiple different forms of natural enemies and also against xenobiotics (Hosokawa et al., 2010; Werren, 2012; Hendry et al., 2014). Parasitic interactions are also known, with the maternal inheritance of the symbiont selecting for sex ratio distortion activity (Hurst and Frost, 2015).

The genus Rickettsia (alpha-proteobacteria) has emerged as an important associate of insects. Members of this genus were classically considered as causative agent of arthropod-borne rickettsioses, which threaten livestock and human health (Gaon and Murray, 1966; Gross, 1996). 
These zoonotic pathogens are endosymbionts of ticks, mites, fleas and lice (Azad and Beard, 1998). Following a bite, the bacteria disseminate into the blood of mammals where it causes disease such as typhus and spotted fever (Gaon and Murray, 1966; Azad and Beard, 1998). In 1994, however, studies of ladybirds (Adalia bipunctata) let to the discovery that Rickettsia can exist strictly as vertically transmitted endosymbionts of arthropods (Werren et al., 1994), with no mammalian transmission. These Rickettsia symbionts are known to present a significant selection pressure on their insect hosts by, for example, altering reproductive success and distorting sex ratio by inducing male-killing in ladybirds (Werren et al., 1994) and parthenogenesis in a parasitoid wasp (Giorgini et al., 2010). Unlike Cardinium, Rickettsiella and Wolbachia, Rickettsia has never been implicated in causing cytoplasmic incompatibility in arthropods (Zabalou et al., 2004; Gotoh et al., 2007; Rosenwald et al., 2020). With regard to host fitness, some Rickettsia strains may aid host defense against pathogens (Hendry et al., 2014).

In 2002, a new group of Rickettsia were discovered during research on Torix tagoi leeches. This Rickettsia infection was associated with changes to leech growth and development, with infected individuals larger than uninfected comparators (Kikuchi et al., 2002; Kikuchi and Fukatsu, 2005). The Rickettsia was a sister group to all other Rickettsia described previously, and the clade were named "torix Rickettsia" (Kikuchi et al., 2002). Torix Rickettsia have since been found across multiple arthropod taxa and seem to be widespread and especially common in species associated with freshwater [e.g., Culicoides midges (Pilgrim et al., 2017), dytiscid water beetles (Küchler et al., 2009), Odonata (Thongprem et al., 2020a), and Amphipoda (Park and Poulin, 2020)], but have also been detected in some terrestrial arthropods, e.g., Araneidae (Goodacre et al., 2006), Siphonaptera (Song et al., 2018), and Hemiptera (Wang et al., 2020). Whilst we now understand symbioses between invertebrates and torix Rickettsia are common, much less is known of their biological significance. This knowledge deficit arises largely from the lack of a good laboratory model systems in which inheritance and biological impact can be measured.

In this study, we characterize the patterns of inheritance and biological impact of torix Rickettsia in the common bed bug (Cimex lectularius). This species is in the order Hemiptera, belonging to the family Cimicidae, all members of which are ectoparasites of warm-blooded animals (Usinger, 1966). Cimex lectularius is a human parasite and its global pest status has medical, social and economic impacts (Hwang et al., 2005; Ribeiro and Valenzuela, 2011). Being an obligate haematophage, C. lectularius have evolved a special organ called a "bacteriome" that harbors Wolbachia, which live as a primary endosymbiont and synthesize B-vitamins to supplement the host's blood diet (Hosokawa et al., 2010). In some individuals, Wolbachia is found alongside a facultative gamma-proteobacterium, also known as BEV-like symbiont (Hosokawa et al., 2010; Meriweather et al., 2013). The impact of this symbiont is not currently understood.

A recent PCR-based screen by Potts et al. (2020) revealed Rickettsia associated with natural populations of C. lectularius in both the UK and the USA. Partial citrate synthase gene ( $g l t A)$ sequences showed that this strain is closely related to the
Rickettsia found in the flea Nosopsyllus laeviceps (Song et al., 2018). Recent work by ourselves has indicated C. lectularius genomic DNA samples from Duron et al. in 2008 (Duron et al., 2008), also carried a Rickettsia symbiont. The analysis revealed the presence of torix Rickettsia in multiple individuals from one laboratory strain, F4.

To explore the torix Rickettsia association with C. lectularius, we undertook PCR assays to investigate the genetic diversity and prevalence of these Rickettsia strains in C. lectularius cultures originally collected from various locations across the UK, Europe and Africa. We isolated two laboratory lines where Rickettsia infection had segregated, and used these to analyse the transmission, tissue tropism and biological impacts of Rickettsia infection. These results indicate a maternally inherited symbiont with a broad somatic/germline distribution, that does not impact host sex ratio or generate cytoplasmic incompatibility. Impacts on host development and reproduction are minor, indicating there likely to be an as yet unelucidated impact on the host.

\section{MATERIALS AND METHODS}

\section{Prevalence of Torix Rickettsia in C. lectularius Populations and Cimicid Allies}

One male and one female adult bed bug from each of 21 lab populations maintained at the University of Bayreuth (Table 1) were sent in $2.0 \mathrm{ml}$ absolute ethanol tubes (one pair/tube) to the lab at the University of Liverpool for DNA extraction. These populations were collected from different areas of Europe and Africa in different years (Table 1). Two populations are of unknown origin in the wild. One of these has been maintained at the Universities of Bayreuth and Sheffield for $>20$ years and before that for $>40$ years at the London School of Hygiene and Tropical Medicine. The other population was received from Bayer (Germany) in 2006.

The samples were rinsed with absolute ethanol and left at room temperature until the samples dried. To avoid contamination with gut microbes, bed bugs were decapitated with sterilized forceps and only the head and/or the upper part (from the head to the thorax, including legs) taken for DNA extraction. Genomic DNA was extracted from the selected body part using Promega Wizard ${ }^{\circledR}$ Genomic DNA Purification kit (A1120, Promega, UK) and DNA dissolved with $100 \mu \mathrm{l}$ of molecular water and stored in $-20^{\circ} \mathrm{C}$ for the future use.

In addition, DNA template was obtained from various species of cimicids from the recently published bed bug phylogeny by Roth et al. (2019) (Table 2). For each species, we received 10 $\mu l$ extracted genomic DNA in $0.2 \mu \mathrm{l}$ tubes from Steffen Roth (University Museum of Bergen, Norway) and Klaus Reinhardt (TU Dresden, Germany), which we stored in $-20^{\circ} \mathrm{C}$ until used. Voucher specimens of some species are stored in the collection of the University Museum of Bergen (ZMNB), Norway.

Initially, all DNA samples were checked for their quality using the invertebrate mtDNA barcoding primers C1J_1718 (Simon et al., 1994) and HCO_2198 (Folmer et al., 1994) (see Supplementary Table 1 ) that amplified a fragment of 
TABLE 1 | Rickettsia infection in Cimex lectularius stock populations in Bayreuth lab.

\begin{tabular}{|c|c|c|c|}
\hline Population name & Origin of place & Year established in Sheffield & Male/Female (M/F) positive \\
\hline $\mathrm{H} 1$ & Budapest, Hungary & 2010 & neither \\
\hline $\mathrm{C} 1$ & Coventry, UK & 2010 & neither \\
\hline Bayer & Bayer Environmental Science, Germany & 2006 & neither \\
\hline $\mathrm{S} 1^{*}$ & London School of Tropical Medicine & 1996 & $(\mathrm{M}) / \mathrm{F}$ \\
\hline London heavy & London, UK & 2006 & neither \\
\hline F11 & London, UK & 2006 & neither \\
\hline $\mathrm{F} 4^{\star}$ & London, UK & 2006 & $\mathrm{M} / \mathrm{F}$ \\
\hline F10 & London, UK & 2006 & neither \\
\hline YMCA & London, UK & 2010 & neither \\
\hline K12 & Nairobi, Kenya & 2008 & $\mathrm{M} / \mathrm{F}$ \\
\hline K4 & Nairobi, Kenya & 2008 & $\mathrm{M} / \mathrm{F}$ \\
\hline K22 & Nairobi, Kenya & 2010 & $\mathrm{M} / \mathrm{F}$ \\
\hline K25 & Nairobi, Kenya & 2010 & $\mathrm{M} / \mathrm{F}$ \\
\hline K26 & Nairobi, Kenya & 2010 & $\mathrm{M} / \mathrm{F}$ \\
\hline K19 & Nairobi, Kenya & 2010 & $\mathrm{M} / \mathrm{F}$ \\
\hline K20 & Nairobi, Kenya & 2010 & $\mathrm{M} / \mathrm{F}$ \\
\hline $\mathrm{K} 7$ & Nairobi, Kenya & 2008 & $\mathrm{M} / \mathrm{F}$ \\
\hline K5 & Nairobi, Kenya & 2008 & $\mathrm{M} / \mathrm{F}$ \\
\hline K30 & Nairobi, Kenya & 2010 & $\mathrm{M} / \mathrm{F}$ \\
\hline BG1 & Sofia, Bulgaria & 2010 & $(\mathrm{M}) / \mathrm{F}$ \\
\hline K17 & Watamu, Kenya & 2010 & neither \\
\hline
\end{tabular}

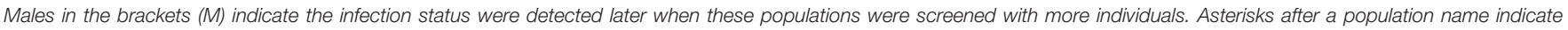

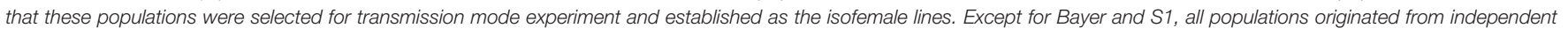
infestations in private homes or youth hostels (Populations H1 and YMCA).

approximately 380 bp of the cytochrome oxidase subunit I (COI) gene of $C$. lectularius. For the samples that passed quality control, we assessed the presence of Rickettsia infections using two Rickettsia-specific primer pairs, targeting 16S rRNA gene, and gltA, the citrate synthase gene (16SrRNA: Ri170_F and Ri1500_R Küchler et al., 2009; gltA, RiGltA405_F and RiGltA1193_R Pilgrim et al., 2017, Primer sequences, cycling conditions and expected amplicon size given in Supplementary Table 1). These primer pairs for Rickettsia are specific for the currently known Rickettsia groups and do not cross amplify other Rickettsiales (Küchler et al., 2009; Pilgrim et al., 2017; Thongprem et al., 2020b). Amplicons were retained for sequencing (see below).

Where we observed only one of the two individuals within a line to be infected with Rickettsia in this initial screen, we screened more individuals (4-10 samples, mixed males and females) to verify the infection status across a wider range of individuals. This screen additionally allowed us to determine if there were any sex-specific patterns of symbiont infection typical of a sex ratio distorting symbiont.

\section{Relatedness of Strains}

The $16 S$ rRNA and gltA amplicons from PCR assays were cleaned with the ExoSAP-IT kit (E1050, New England Biolabs, US) and Sanger sequenced. The sequence chromatograms were trimmed and edited in UGENE (Okonechnikov et al., 2012). All the sequences were exported to fasta format and searched against other Rickettsia strains on NCBI database to find close relatives ascertained by BLAST homology. The sequence of these markers from closely related Rickettsia strains from other invertebrate hosts were retrieved, and the relatedness within the torix group estimated. Other Rickettsia strains from other clades, e.g., Rickettsia bellii and vertebrate pathogens were selected to represent the sister group to the torix clade. Occidentia massiliensis was use as the outgroup for both topologies. All the selected sequences were aligned with Rickettsia sequences in this study using MUSCLE algorithm with its default setting in MEGA X (Kumar et al., 2018; Stecher et al., 2020). The ML phylogeny for both genes were estimated in MEGA $\mathrm{X}$ with 1,000 rapid bootstrap replicates under $\mathrm{T} 92+\mathrm{I}$ and $\mathrm{K} 2+\mathrm{I}$ model for glt A and $16 \mathrm{~S}$ gene, respectively.

\section{Transmission Mode Experiment}

To investigate the vertical transmission mode of torix Rickettsia, we used two bed bug lab populations, S1 and F4, both of which we had found to contain a mix of infected and uninfected individuals. We randomly selected males and females to establish 55 and 49 mating pairs for S1 and F4, respectively, from which we reared offspring. The parents and 5-10 randomly selected first instar nymphs per cross were screened for torix infection status using the PCR assays as described above. First-instar nymphs were tested individually to gain insight into vertical transmission efficiency, and whole bodies were used for template. We then assessed the impact of parental infection status (mother infected, father infected) on progeny infection status. 
TABLE 2 | Rickettsia infection in cimicid allies.

\begin{tabular}{|c|c|c|c|c|c|}
\hline Subfamily & Species & $N$ & Locality & Year of collection & Infection \\
\hline Afrocimicinae & Afrocimex constrictus & 3 & Kenya & 2005 & + \\
\hline \multirow[t]{2}{*}{ Primicinae } & Bucimex chilensis & 1 & Chile & 2013 & - \\
\hline & Primicimex cavernis & 1 & Mexico & 2015 & - \\
\hline \multirow[t]{7}{*}{ Haematosiphoninae } & Acanthocrios furnarii & 1 & Brazil & 2010 & - \\
\hline & Cimexopis nyctalis & 1 & USA & 2016 & - \\
\hline & Cyanolicimex patagonicus & 1 & Argentina & 2003 & - \\
\hline & Hesperocimex coloradensis & 1 & Los Alamos County, N.Mex. & 1971 & - \\
\hline & H. sonorensis & 1 & Mexico & 2017 & - \\
\hline & Psitticimex uritui & 1 & Argentina & 2008 & - \\
\hline & Ornithocoris pallidus & 1 & USA, South Carolina & 2010 & - \\
\hline \multirow[t]{5}{*}{ Cimicinae } & Cimex hemipterus & 1 & Taiwan & Before 1966 & - \\
\hline & C. hirundinis & 1 & Switzerland & $\mathrm{N} / \mathrm{A}$ & - \\
\hline & C. pipistrelli & 1 & Hanau, Germany & 2004 & - \\
\hline & Paracimex borneensis & 1 & Borneo & 2015 & - \\
\hline & P. inflatus & 1 & Kavieng, Papua New Guinea & 1996 & - \\
\hline \multirow[t]{6}{*}{ Cacodminae } & Aphrania elongata & 1 & Senegal & 2012 & - \\
\hline & A. vishnou & 1 & Phnom Penh, Cambodia & 1952 & - \\
\hline & Cacodmus villosus & 1 & Kenya & 2005 & - \\
\hline & Leptocimex boueti & 1 & $\mathrm{~N} / \mathrm{A}$ & N/A & - \\
\hline & L. duplicatus & 1 & Israel & 2002 & - \\
\hline & Loxapsis malayensis & 1 & Tasik Bera, Pahang, Malaysia & 1962 & - \\
\hline
\end{tabular}

The infection found in all individuals of Afrocimex constrictus but absent in other tested species.

\section{Isofemale Lines and Bed Bug Culture}

Based on the infection status of offspring from the transmission mode experiment, we established four Rickettsia-free (R-) and four Rickettsia-infected $(\mathrm{R}+)$ isolines for each of the F4 and S1 populations. These isofemale lines of known Rickettsia infection status were then kept under constant conditions, in a CT room at $26 \pm 1^{\circ} \mathrm{C}$, at about $70 \%$ relative humidity with a cycle of 12L:12D. We additionally tested all isofemale lines for the BEV-like bacterium infection using a PCR assay as described in Degnan et al. (2011) (Supplementary Table 1). New generations were set up regularly, i.e., at a 6-8-week interval. Each new generation was started with randomly picked virgin female and virgin male. All bed bugs were maintained in the CT room with the conditions described as above. All individuals in our study were virgin prior to experiments. The feeding, maintenance and generation-of-virgin-individuals protocols follow Reinhardt et al. (2003).

\section{Fluorescence in situ Hybridization (FISH)}

To localize the torix Rickettsia and other symbionts within the C. lectularius body, we used the FISH technique adapted from Sakurai et al. (2005). We investigated the bacteriome and reproductive tissue in virgin male and female adults, as well as the whole body of first instar nymphs from the R+ and R- F4 and S1 lines. Tissues were dissected in 0.5M PBS at pH 7.4 and preserved immediately in Carnoy's solution (chloroform: ethanol: glacial acetic acid $=6: 3: 1$ ) overnight. Bedbug nymphs were preserved in the solution without dissection. All tissue samples were cleared by incubating in $6 \% \mathrm{H}_{2} \mathrm{O}_{2}$ in ethanol for $12 \mathrm{~h}$, save for the whole-body nymph that was incubated at least $24 \mathrm{~h}$ or until the body was transparent. We then used a tungsten micro-needle to make micropores in the nymph cuticle to allow the fluorescence probes to pass through the cuticle during the hybridization step. The samples were hybridized by incubating the tissues overnight in a hybridization buffer $(20 \mathrm{mM}$ Tris- $\mathrm{HCl} \mathrm{pH} 8.0$, $0.9 \mathrm{M} \mathrm{NaCl}, 0.01 \%$ Sodium dodecyl sulfate $30 \%$ formamide) with $10 \mathrm{pmol} / \mathrm{ml}$ of $\mathrm{rRNA}$ specific probes for Rickettsia (Perotti et al., 2006), Wolbachia (Hosokawa et al., 2010), and Gamma proteobacteria (BEV-like symbiont) (Hosokawa et al., 2010) (probe sequences in Supplementary Table 1). We also used nuclei fluorescence staining, Hoechst 33342 (H1399, Invitrogen, Carlsbad, USA), to visualize bed bug tissues. After incubation, tissues were washed in buffer $(0.3 \mathrm{M} \mathrm{NaCl}, 0.03 \mathrm{M}$ sodium citrate, $0.01 \%$ sodium dodecyl sulfate) and mounted onto a slide using VECTASHIELD ${ }^{\circledR}$ Antifade (H-1000, Vectorlabs, UK) as a mounting medium. Slides were then observed under a confocal microscope, 880 Bio AFM (on 880 LSM platform, ZEISS, Germany).

\section{Development Time and Sex Ratio Produced by Rickettsia Infected and Uninfected Individuals in a Common Garden Experiment}

A 7-day-old virgin male and female from each isofemale line were placed together in a pot and allowed to mate. Individuals from both sexes were fully fed as post-eclosion 
adults, and also immediately prior to mating, which ensured gamete production until day 7 . Once offspring hatched from the eggs laid, we collected 10 first instar nymphs from each pot $(N=160)$. We then prepared eight fresh pots with a filter-paper and randomly assigned each group of $10 \mathrm{R}+$ and $10 \mathrm{R}$ - nymphs to a pot and presented them with the opportunity to feed every 3 days. As soon as the first 5 th instar nymph was observed in a pot, eclosion was checked every day. Freshly eclosed adults were then removed from the pot and post-hoc screened for Rickettsia infection status using the PCR assays described above. The number of days between placement into the pot and the last hatching event, i.e., removal from the pot, represents the development time. The sex of individuals was determined when the bugs reached the adult stage. Sex ratio (number of female:male) was calculated and compared between the two infection status, $\mathrm{R}+$ and R- individuals, which were identified with PCR assays as described above.

\section{Effect of Rickettsia Infection on Fecundity and Cytoplasmic Incompatibility}

To measure the effect of Rickettsia infection on fecundity we used a full factorial crossing scheme of female $\mathrm{x}$ male, i.e., $\mathrm{R}+\times \mathrm{R}+$, $\mathrm{R}+\times \mathrm{R}-, \mathrm{R}-\times \mathrm{R}+$ and $\mathrm{R}-\times \mathrm{R}-$. For this, we prepared sameaged individuals by putting a 7 -day-old virgin male and female together in a pot and allowing them to mate and feed weekly. Every week we collected all the eggs and put them in a fresh pot, which was fed weekly until 5th instar nymphs were observed. Same-aged 5 th instars were then fed and placed into a 96-well plate until they reached adulthood. Seven-day-old virgin adults were then used in a full factorial crossing experiment. Prior to the experiment, females were fed twice, the last time on the day of mating, and males once, on the day of hatching. To avoid inbreeding effects, each isofemale line was crossed with every other line, but not with itself. To have equal sample sizes for within vs. between $\mathrm{R}+$ and $\mathrm{R}$ - crosses we randomly left one cross out. In this manner, we crossed each isofemale line with three $\mathrm{R}+$ lines and with three $\mathrm{R}-$ lines ( $N=96$ crosses). Matings were staged, monitored and interrupted after $60 \mathrm{~s}$ as described earlier in Reinhardt et al. (2009a). Interrupted matings were conducted to standardize sperm number because of the linear relationship between copulation duration and sperm number (Siva-Jothy and Stutt, 2003). A standardized sperm number was desirable since spermatozoa trigger the release of an ovipositionstimulating hormone from the corpora allata (Davis, 1956) and could potentially influence lifespan through differential egg production. The use of $60 \mathrm{~s}$ standard copulation also allows comparability with other studies.

After mating, the females were kept individually in $15 \mathrm{ml}$ plastic tubes equipped with a piece of filter paper for egg laying. Females were fed weekly and the number of fertile and infertile eggs counted in weekly intervals. Fertile and infertile eggs were distinguished following Reinhardt et al. (2009b). Fertile eggs are taut and whitish with visible eye spots of the developing embryo. Infertile eggs normally collapse soon after being laid and are grayish. The number of fertile eggs was used to investigate the fecundity of crosses.

To determine the occurrence of CI, we observed the number of fertile eggs produced by females from different crossing combinations (Sakamoto and Rasgon, 2006). When fertile eggs are laid, it implies that the embryos in the eggs have already passed the critical point of CI. It has been observed that about one-third of embryogenesis happens within the ovaries before the eggs are laid (Usinger, 1966). We expected that if Rickettsia induces CI in the bed bug, the proportion of fertile eggs will be lowest in the group that only males from Rickettsia-infected line were crossed $(\mathrm{R}-\times \mathrm{R}+)$.

\section{Statistical Analyses}

The data were analyzed using the statistical platform $\mathrm{R}$ (version 3.6.1, 2019) ( $\mathrm{R}$ Development Core Team, 2019) using the packages "lme4" (Bates et al., 2015). The analysis of development time and fecundity were done by fitting linear mixed-effects models (LMMs) using the "lmer" function, while sex ratio and cytoplasmic incompatibility were fitted in generalized linear mixed effect model (GLMMs) using "glmer" function with binomial family.

For the development time and sex ratio, we fitted "pot" as a random effect in mixed effect models, while "infection status" and bed bug "populations" were fitted as the fixed effect in all cases. The factor "sex" was also included as a fixed effect explaining development time. The ratio of "female: male" and "number of fertile: infertile eggs" were set as the response variable in the sex ratio and fecundity test, respectively. In fecundity and CI analyses, "infection status" was broken down into "male infection status" and "female infection status" as these two factors represented cross types (female $\mathrm{x}$ male; $\mathrm{R}+\times \mathrm{R}+, \mathrm{R}+\times \mathrm{R}-, \mathrm{R}-$ $\times \mathrm{R}+, \mathrm{R}-\times \mathrm{R}-$ ), alongside the fixed effect "population." Family of origin was modeled as a random effect.

Non-significant effects were removed from the models until we found the minimum adequate model. We performed Likelihood ratio test (LRT) by comparing the minimum adequate models of both LMMs and GLMMs with a null model using "anova" function, considering by $\chi^{2}$ with critical $p$-value at 0.05 . The normality and homoscedasticity of residuals of the LMMs models were validated before the final interpretation.

\section{RESULTS}

\section{Torix Rickettsia Across Bed Bug Populations and Other Cimicids}

DNA extractions from each C. lectularius population and all cimicid allies passed QC, with good amplicons in the COI amplification. Thirteen out of 21 C. lectularius populations tested positive to Rickettsia infection with both $16 \mathrm{~S}$ rRNA and gltA primers. These populations have their origin in Africa and Europe (Table 1). Both male and female individuals were found to be infected in most cases where infection was detected. In the initial screen, the female individual alone was scored as infected in populations S1 and BG1; however, infection in males was observed in both populations on deeper screening (Table 1). For the cimicid allies, PCR results indicated that only one 
A

Rickettsia groups
Torix
Rhyzobius
Bellii
Transition
Spotted fever
Occidentia (outgroup)

99

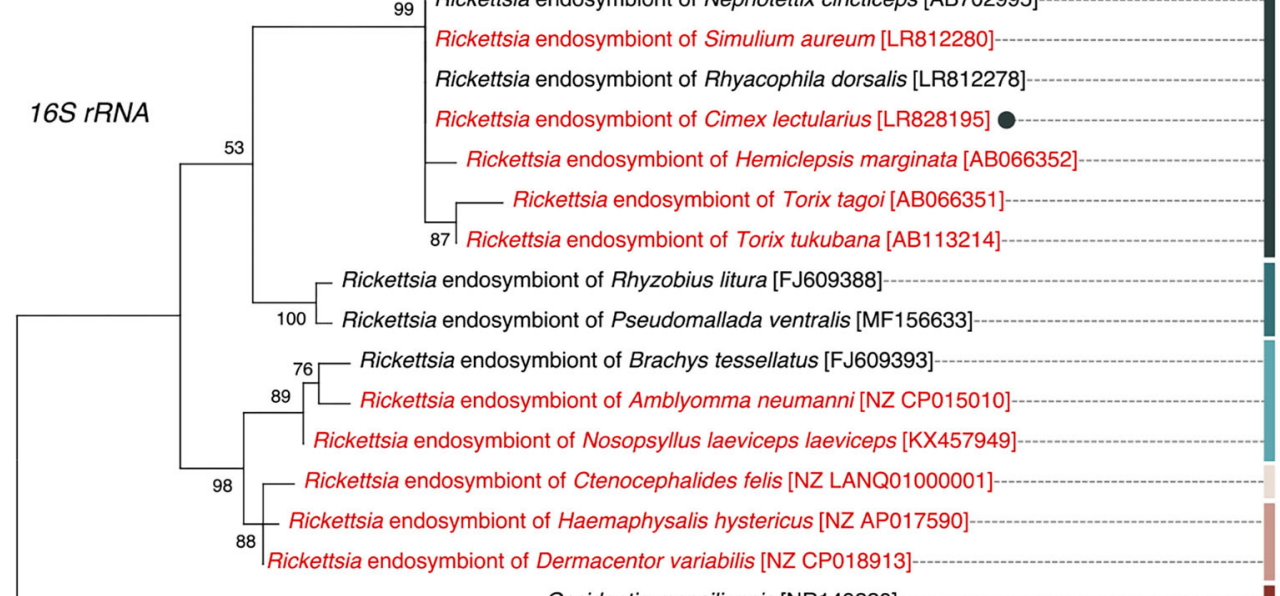

Occidentia massiliensis [NR149220]-
Araneae

Diptera

Diptera

Odonata

Odonata

Hemiptera

Coleoptera

Hemiptera

Diptera

Trichoptera

Hemiptera

Hirudinea

Hirudinea

Hirudinea

Coleoptera

Neuroptera

Coleoptera

Ixodida

Siphonaptera

Siphonaptera

Ixodida

Ixodida

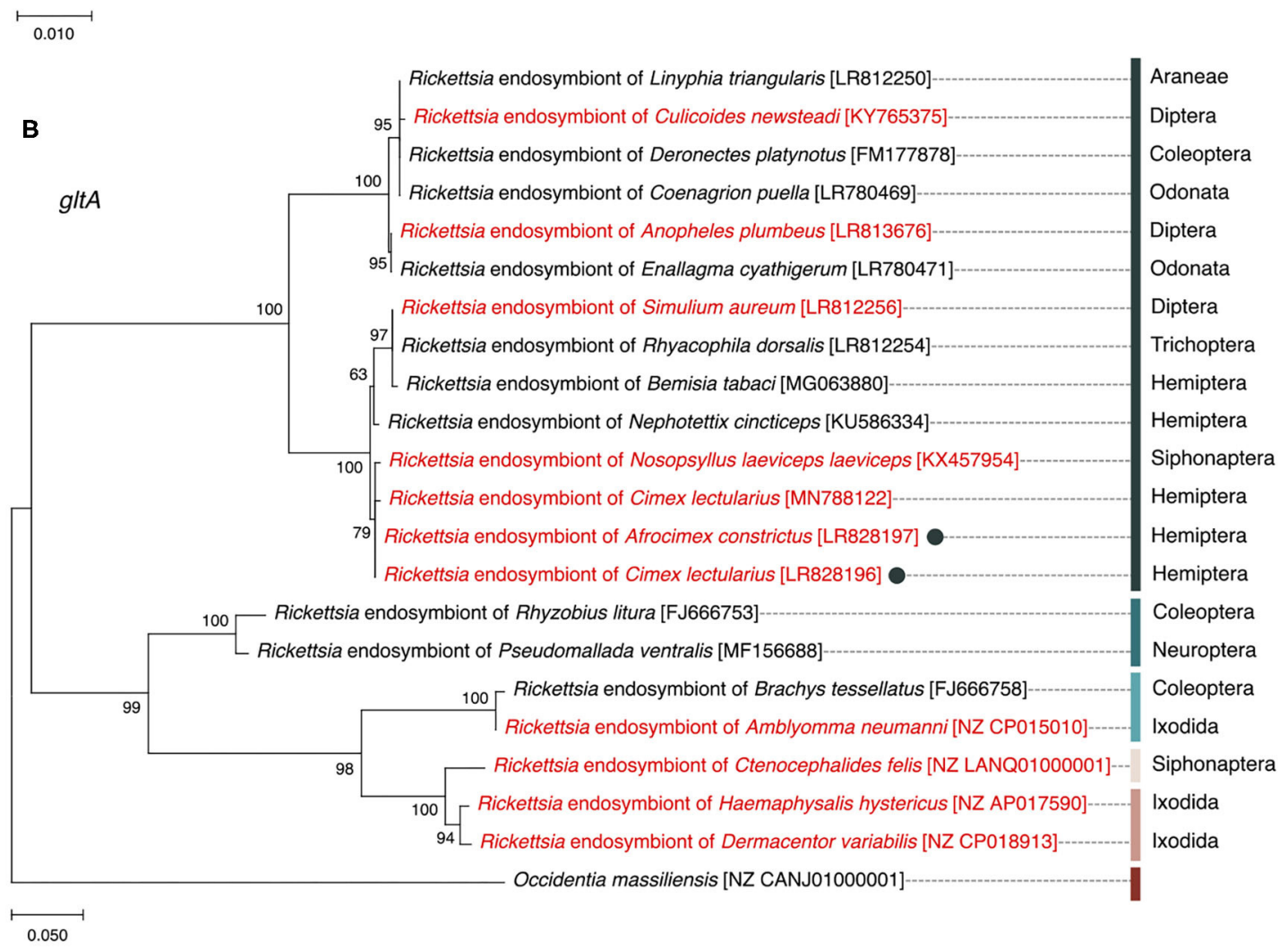

FIGURE 1 | Maximum likelihood phylogenetic trees generated from 16S rRNA gene (A) and gltA gene (B) sequences showing the position and relatedness of Rickettsia endosymbiont of $C$. lectularius and $A$. constictus found in this study (filled circles) in relation to other strains obtained from NCBI (the GenBank accession 
FIGURE 1 | numbers are in the square brackets). Rickettsia from blood-feeder hosts are shown in red color. Scientific order names of arthropod hosts are provided at the end of the leaves while scientific class names are given for non-arthropod hosts. Bootstrap support values, expressed as the percentage of 1,000 replicates, are shown at the nodes. Bars indicate substitution nucleotide per position.

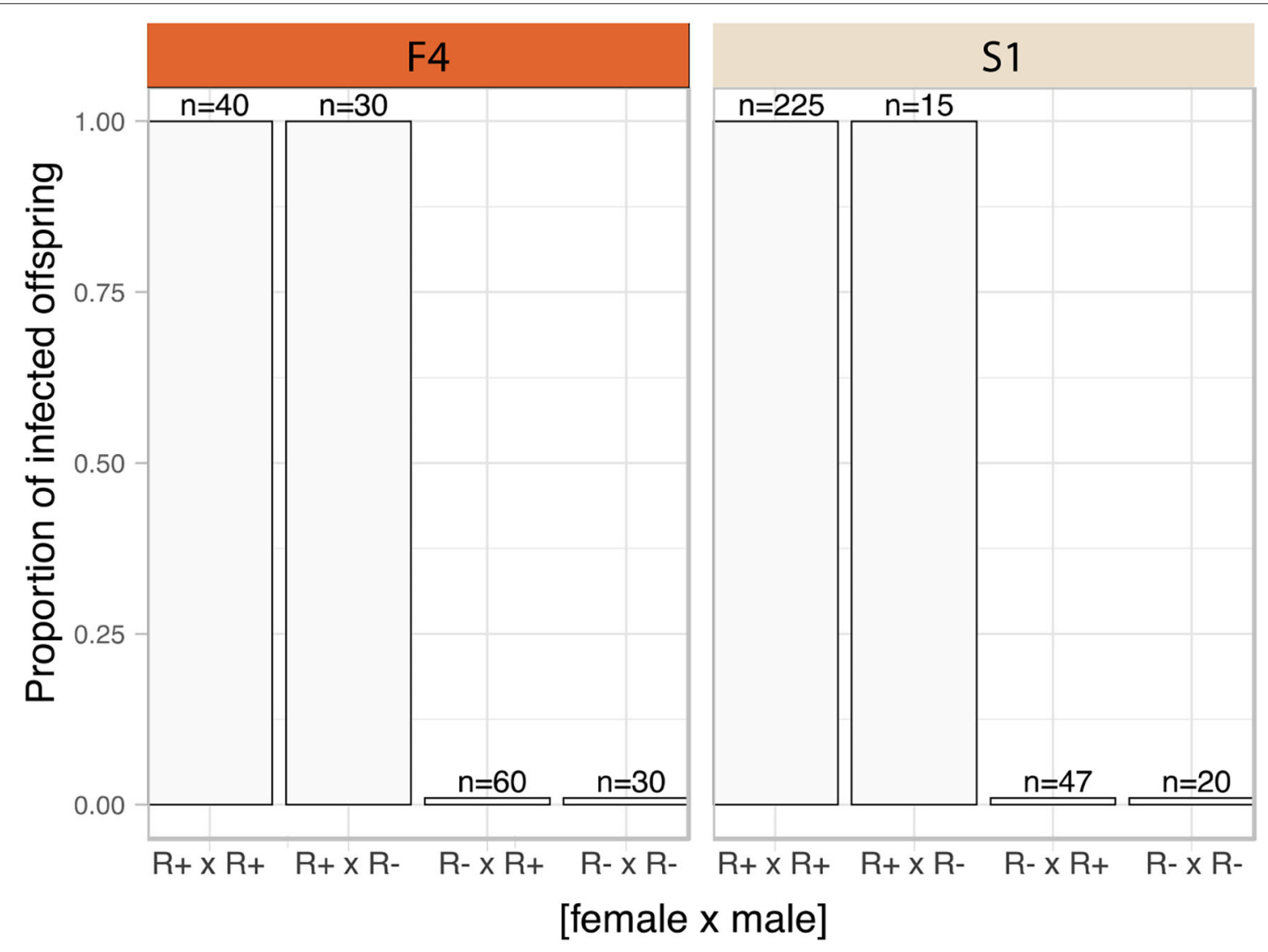

FIGURE 2 | Transmission mode of $C$. lectularius associated Rickettsia. The bars indicate proportion of infected offspring in each crossing group. The four crosses were sorted by infection status of the parents, female $\times$ male $(\mathrm{R}+\times \mathrm{R}+$ : 8 crosses for F4, 45 for S1; R+ $\times$ R-: 6 crosses for F4, 3 for S1; R- $\times$ R+: 12 crosses for F4, 5 for S1; for R- $\times$ R-: 23 crosses for F4, 2 for S1). No infected offspring were observed from Rickettsia-free mother groups (R- $\times$ R+ and R- $\times$ R-).

species, Afrocimex constrictus in one subfamily Afrocimicinae, were positive for Rickettsia infection with all three samples scoring positive (Table 2). However, the rickettsial PCR only produced gltA amplicons for this species, despite repeated attempts at $16 \mathrm{~S}$ amplification.

\section{Phylogenies}

The 16S rRNA sequence alignment of all Rickettsia strains from the C. lectularius populations indicated that these strains were identical (based on 985 bp sequence length information, accession number; LR828195). The phylogenetic tree based on $16 S$ rRNA gene showed the Rickettsia strain of C. lectularius is placed in torix group (Figure 1). The alignment of gltA sequences (746 bp) of C. lectularius also showed no variable sites across all Rickettsia positive populations. Moreover, the sequences of the gltA amplicons from both $C$. lectularius and A. constrictus (accession numbers; LR828196-LR828197) were also identical (Figure 1).

\section{Transmission Mode Experiment}

The frequency of infected parents in the F4 population was lower than that in S1 (F4: 14 of 49 mothers, and 20 of 49 fathers carried the symbiont; S1 population, 48 of 55 mothers, and 50 of 55 fathers carried the symbiont). The Rickettsia infection status for each family was categorized into four groups according to parental infection status. Rickettsia transmission to progeny was consistently observed where either both parents $(\mathrm{R}+\times \mathrm{R}+)$ or just the mother $(\mathrm{R}+\times \mathrm{R}-)$ tested positive for torix Rickettsia $(\mathrm{R}+$ $\times \mathrm{R}+:$ F4: 8 crosses, S1: 45 crosses; R+ $\times$ R-: F4: 6 crosses, S1: 3 crosses) (Figure 2). In these cases, all 310 tested nymphs tested positive for infection, indicating vertical transmission through females was highly efficient (Confidence intervals for vertical transmission efficiency $0.988-1.000$ ). No progeny tested positive for Rickettsia infection in families where only the father was infected ( $\mathrm{R}-\times \mathrm{R}+$ : F4: 12 crosses, S1: 5 crosses), nor were any Rickettsia positive individuals recovered from crosses where neither parent was infected $(\mathrm{R}-\times \mathrm{R}-\mathrm{f}$ F4: 23 crosses, S1: 2 


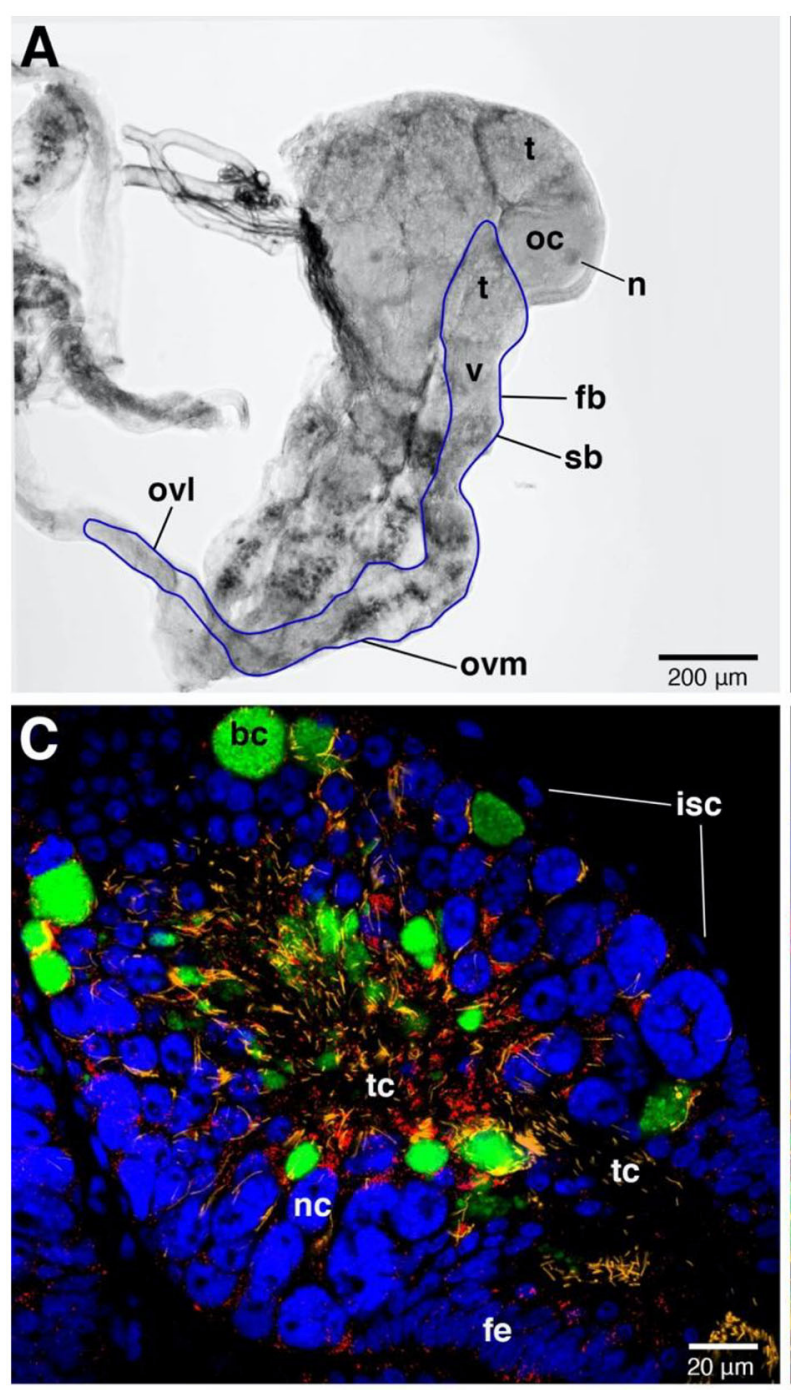

B
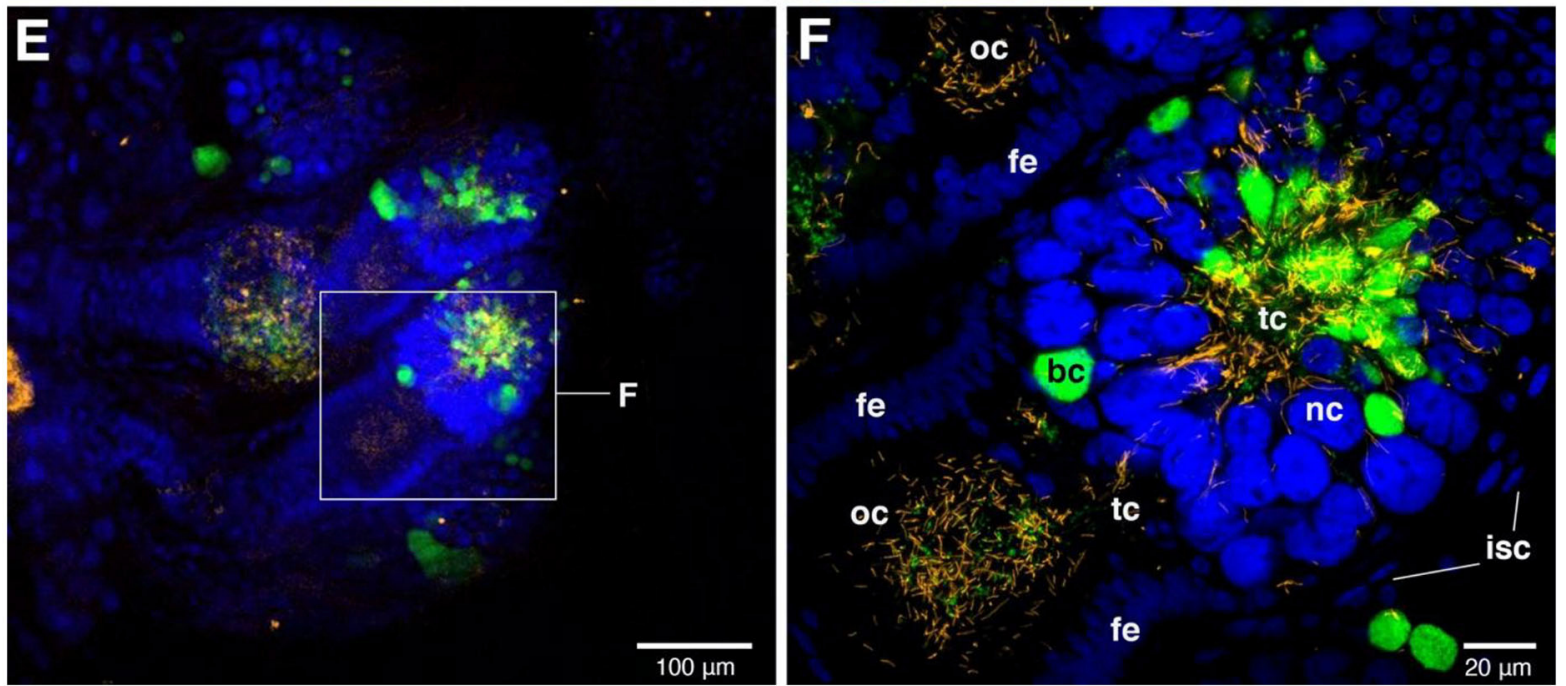

FIGURE 3 | FISH images of adult female ovaries. (A) Bright field image of one-sided ovaries from Rickettsia-infected female. The blue line represents the outline of one ovariole. $\mathrm{n}=$ nucleus of oocyte, $\mathrm{t}=$ tropharium part, $\mathrm{v}=$ vitellarium part, $\mathrm{fb}=$ follicular body, oc $=$ oocyte, ovl $=$ lateral oviduct, ovm $=$ mesodermal oviduct, 
FIGURE $3 \mid \mathrm{sb}=$ syncytial body. (B) FISH shows the presence of the three symbionts, i.e., Wolbachia (green), BEV-like symbionts (yellow), and Rickettsia (red) in ovaries. Blue color represents nuclei of bed bug cells. The signals of three symbionts are concentrated in tropharium areas. Small rectangles indicate the magnified fields of tropharium and vitellarium portions, showing in (C,D), respectively. Rickettsia (filled triangles) and BEV-like symbionts (open triangles) are also detected in syncytial body and mesodermal oviduct at low densities. (C) Enlarged detail of the tropharium portion. It is covered by a membrane of inner sheath cells (isc). The three symbionts distribution can be detected at very high density in all along the trophic core (tc) area. Wolbachia are likely packed in bacteriocytes (bc) which are distinctive to the adjacent nurse cells (nc), while Rickettsia and filamentous BEV-like symbionts are more scattered. (D) Enlarged detail of vitellarium portion. All three symbionts invade the oocyte, forming a cluster at the posterior pole of the oocyte. Rickettsia signals are scattered insertions in the follicular epithelium (fe) of the oocyte. (E) Ovaries of Rickettsia-free bed bug. Only Wolbachia and BEV-like symbionts are present. The small rectangle represents the tropharium and vitellarium parts of one ovariole, showing in (F). (F) Enlarged field of partial upper ovariole. The distribution of Wolbachia and BEV-like symbionts are intensive in trophic core and in oocyte. None Rickettsia signals are detected here.

crosses). These data indicate that maternal infection is necessary and sufficient for presence of Rickettsia in progeny, and there is no evidence of paternal inheritance. The PCR assay for the BEVlike symbiont revealed that all individuals within these crosses were infected with this symbiont.

\section{Localization of the Symbionts}

FISH detected Rickettsia throughout ovaries and bacteriome tissues (Figures 3, 4). In adult females, the distribution of the Rickettsia signal was intense in the core of the tropharium and in oocytes. We observed the filamentous BEV-like symbiont and Wolbachia alongside Rickettsia in this tissue. In comparison to the other symbionts, Rickettsia were more widely distributed in the ovaries. We observed them additionally in nurse cells and follicular epithelial cells (Figures 3C,D). Rickettsia signals were absent in R- bed bugs (Figures 3E,F). The pattern of Rickettsia infection was similar between the F4 and S1 populations.

Rickettsia signals were found in somatic tissue of the abdominal areas of first instar whole mounts, alongside the BEVlike symbiont (Figure 4B). At low magnification, the strongest signal (green color) was emitted by Wolbachia, reflecting the intense infection of bacteriome organs (Figure 4B). Rickettsia and the BEV-like symbiont, however, could also be seen at this low magnification but poorly resolved. At the higher magnification, Rickettsia is clearly visible in the bacteriome alongside Wolbachia and the BEV-like symbiont as all the three signals were reliably present in this tissue (Figures 4D,E). Again, a similar pattern of Rickettsia infection was observed in F4 and S1 populations. In R- samples, only the signals of Wolbachia and the BEV-like symbiont were present, while Rickettsia signals were absent (Figure 4C).

\section{Development Time and Sex Ratio}

Development showed a different pattern between the populations. In F4 the development times were similar across all four crosses (Figure 5). S1 showed a substantial difference between the development time of $\mathrm{R}+$ and $\mathrm{R}-$ females, whereas $\mathrm{R}+$ and $\mathrm{R}$ - males were the same (Figure 5). The full model analysis (including interaction terms between sex, population and Rickettsia infection status) was not a significantly better fit than the model without interaction terms (LRT $\left.\chi^{2}(4)=5.554, p=0.235\right)$.

The impact of individual terms was then examined in models without an interaction term. The only significant explanatory variable was "infection": LRT of models with and without infection term: $\left.\chi^{2}(1)=5.177, p=0.023\right)$. First instar-adult period for Rickettsia infected individuals increased by $0.59 \pm$ 0.26 days (Mean $\pm \mathrm{SD}$ ). The Rickettsia-infected line took $26.7 \pm$ 2.00 days to reach adulthood $(N=78)$ while the bugs from the Rickettsia-free line took $25.9 \pm 2.15$ days $(N=72)$ (Figure 5). Population and sex were not observed to explain variation in development time.

There was no impact of Rickettsia infection status on the sex ratio of offspring (LRT: $\chi^{2}(1)=0.0003, p=0.985$ ) (Figure 6). Female: male ratio of the Rickettsia-free group was $0.84 \pm 0.29$ and $0.93 \pm 0.67$ for the Rickettsia-infected group. The interaction effect between infection status and population of origin was not statistically significant (LRT: $\chi^{2}(1)=0.078, p=0.780$ ).

\section{Fecundity and Cytoplasmic Incompatibility}

We analyzed fecundity (total fertile eggs) using likelihood ratio comparison of LMMs. There was no evidence of an interaction effect between the three factors, i.e., population, male, and female infection status (LRT: $\chi^{2}(3)=5.781, p=0.216$ ), and these terms were dropped from the model. The final model detected Rickettsia infection in female parent as the sole significant explanatory variable for fecundity (LRT: $\chi^{2}(1)=4.576, p=$ 0.032 ). Infected females were likely to produce fewer fertile eggs $(\mathrm{R}+\times \mathrm{R}+=86.80 \pm 34.30, \mathrm{R}+\times \mathrm{R}-=89.70 \pm 28.30)$ compared to non-infected females $(\mathrm{R}-\times \mathrm{R}+=107.00 \pm 34.90$, $\mathrm{R}-\times \mathrm{R}-=109.00 \pm 34.60$, Figure 7A).

We then analyzed the relative ratio of fertile:infertile eggs to ascertain if there was any evidence of cytoplasmic incompatibility. There was no evidence of heterogeneity associated with Rickettsia infection in either male (LRT: $\chi^{2}(1)$ $=0.593, p=0.441)$ or female parents (LRT: $\chi^{2}(1)=1.174, p$ $=0.279$ ). There was no evidence of an interaction term between male infection $\mathrm{x}$ female, evidence by the statistical equivalence of models with and without an interaction term (LRT: $\chi^{2}(4)$ $=6.725, p=0.151$, Figure 7B). However, the number and proportion of fertile eggs was higher in $\mathrm{F} 4$ when the males were $\mathrm{R}$ - whilst the opposite was the case for S1, where both variables were higher when the males were $\mathrm{R}+$.

\section{DISCUSSION}

Torix Rickettsia are common associates of insects and other invertebrates, but their mode of transmission and impact on the host are poorly understood. In the present study, we examined the interaction between torix Rickettsia and C. lectularius, a notorious pest of humans. In line with other recent work, our 


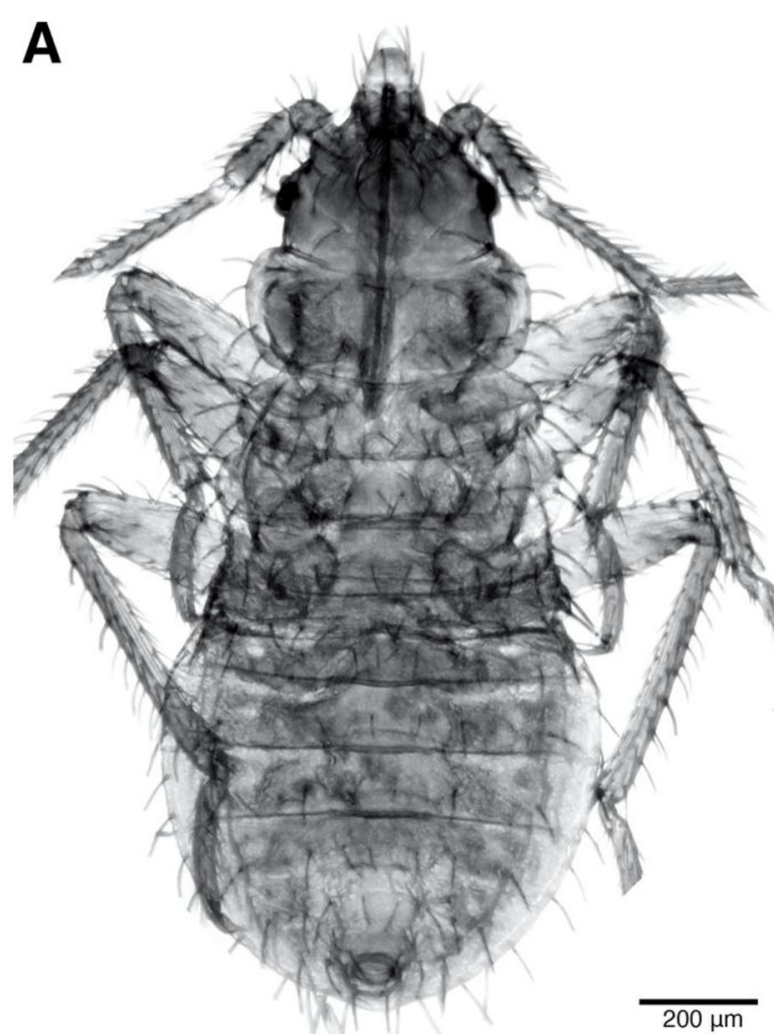

B
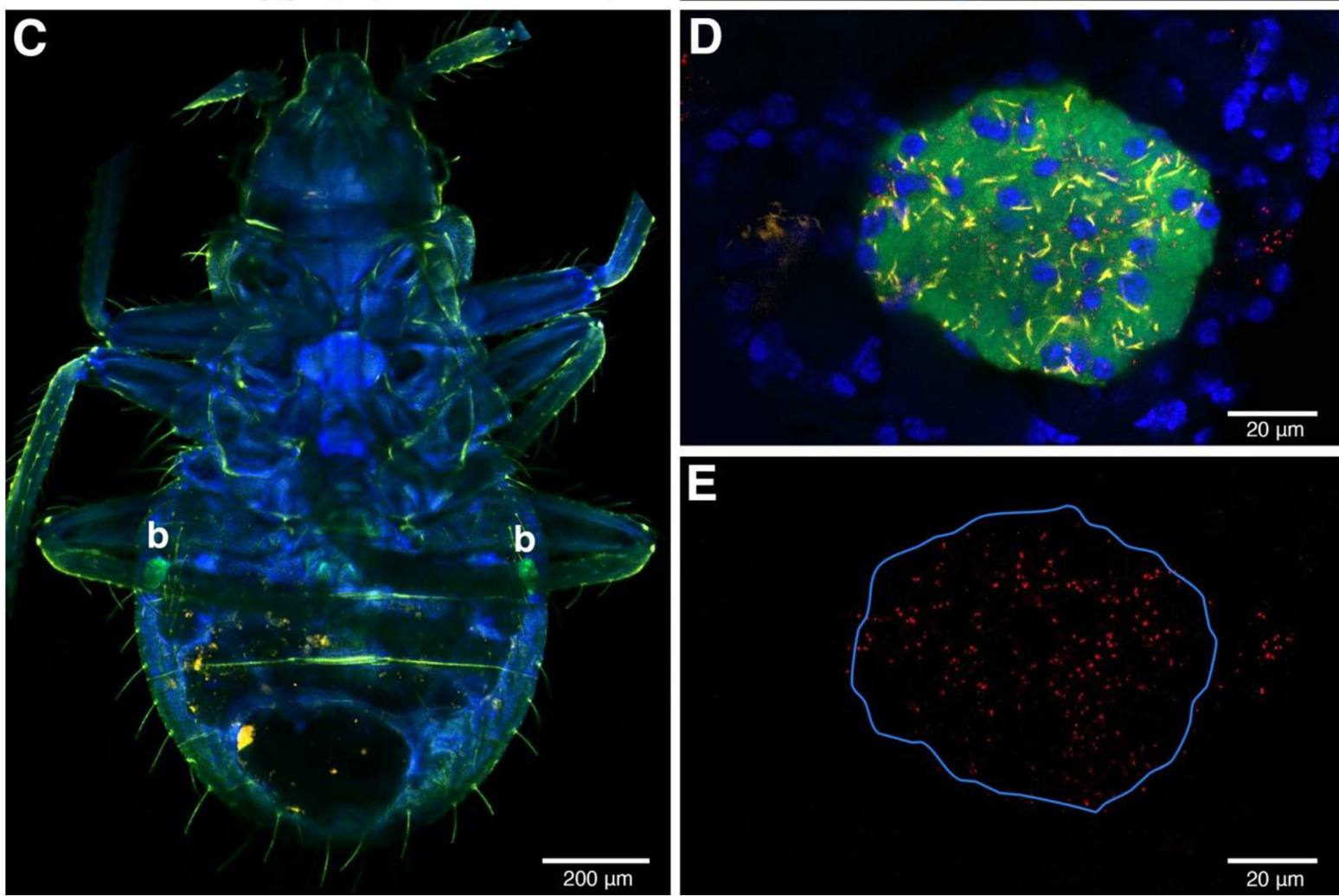

FIGURE 4 | FISH image of whole-mounted first instars. (A) The nymph under transmitted light. (B,C) FISH detection of symbionts in Rickettsia-infected (B) and Rickettsia-free instars (C). The ball-shaped with green fluorescent color represents strong Wolbachia signals, indicating the bacteriome (b) position in the abdomen. 
FIGURE 4 | Rickettsia infection in red (filled triangles) present in (B) but absent in (C,D) Bacteriome of Rickettsia-infected instar. All the three symbionts can be detected in this organ. Wolbachia, BEV-like symbionts and Rickettsia are in green, yellow, and red, respectively. The blue color represents nuclei of bed bug cells. (E) The same field as (D) but only the Rickettsia channel remains. The blue line indicates the bacteriome boundary.

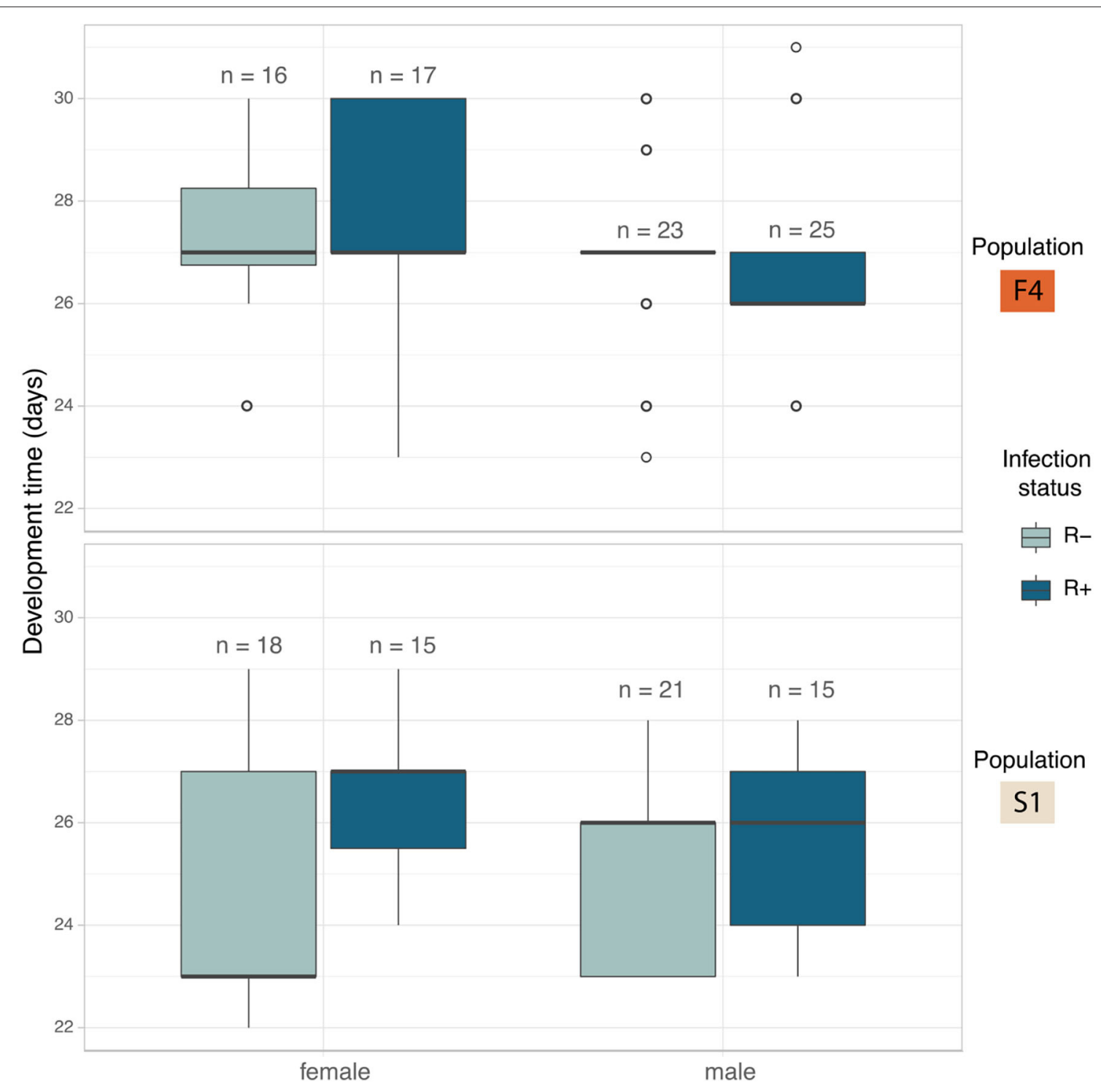

FIGURE 5 | Median development time in days of $C$. lectularius from the first instar to adulthood for males and female individuals of Rickettsia-free (R-, light blue) and Rickettsia-infected ( $\mathrm{R}+$, dark blue) groups from population F4 (top) and S1 (below). Rickettsia infection has a significant effect on development time (LRT: $\chi^{2}(1)=$ 5.177, $p=0.023$ ). Boxes indicate the 25 and 75 percent quartiles, respectively, the whiskers show minimum and maximum values. Open circles indicate potential outliers.

PCR screen revealed Rickettsia were commonly found in bed bug lines maintained in the laboratory with only a single Rickettsia strain detected. Segregation of the Rickettsia in two lines was observed - with a mix of infected and uninfected individuals being observed in laboratory populations. The polymorphism in Rickettsia presence allowed us to isolate isogenic $\mathrm{R}+$ and $\mathrm{R}$ - cultures and then use these to analyse transmission and impact on the host. We observed that the symbiont showed high fidelity maternal inheritance, but no transmission through males. Consistent with this, Rickettsia infections were present in ovaries, as well as in the bacteriomes. Infection with this symbiont did not impact host sex ratio and did not induce cytoplasmic incompatibility, but there was evidence it slowed development to the adult stage and reduced female fecundity.

In this study, the Rickettsia strain detected in C. lectularius and $A$. constrictus are placed in the non-vertebrate pathogen 


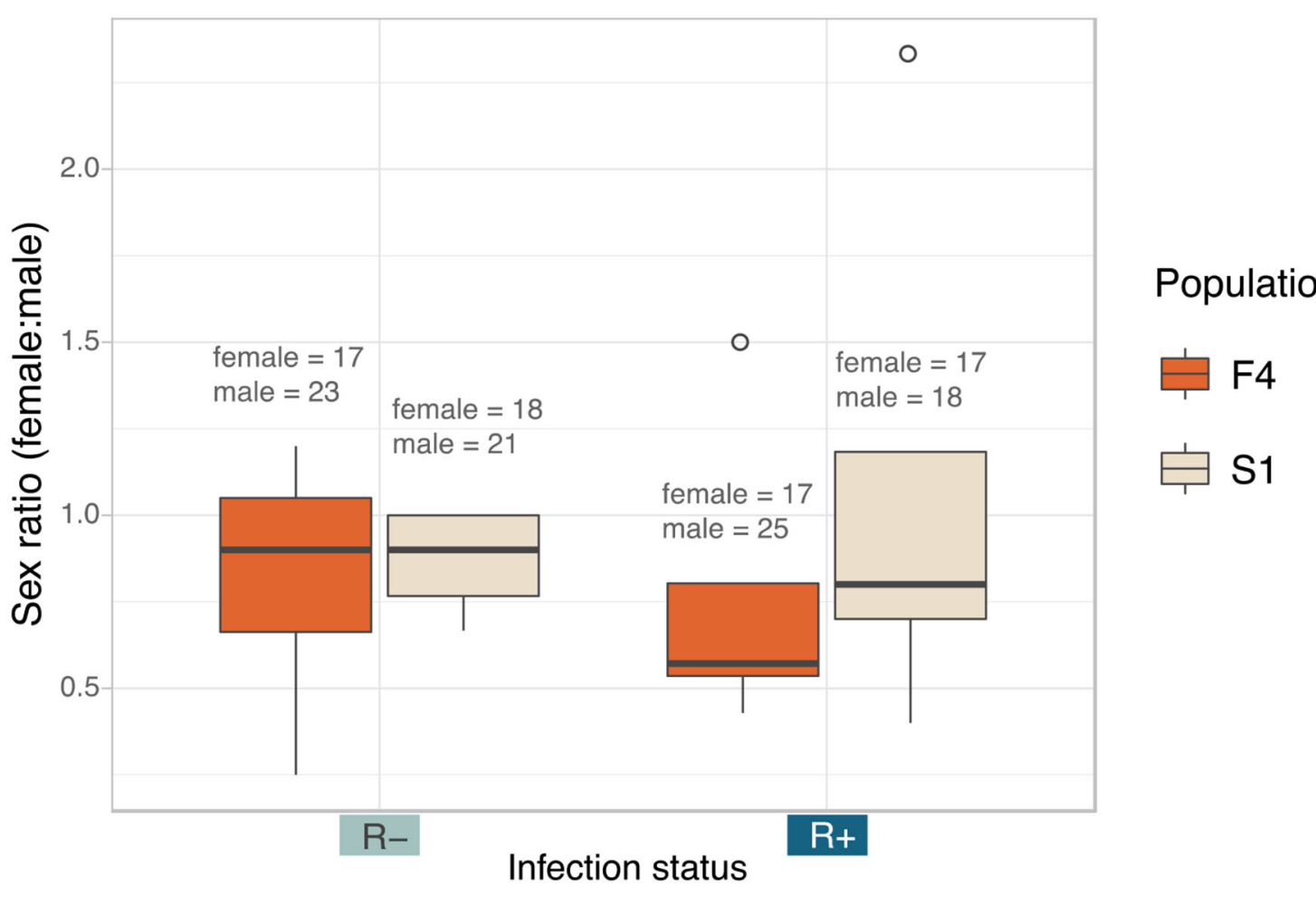

FIGURE 6 | Median sex ratio (number of female:male) of the Rickettsia-free and Rickettsia-infected C. lectularius adults from the two populations. The sexes were identified from adult bed bugs. There was no significant different of the sex ratio between $\mathrm{R}$ - and $\mathrm{R}+$ group at $p=0.05$. Total number of males and females are shown above the boxes. Boxes indicate the 25 and 75 percent quartiles, respectively, the whiskers show minimum and maximum values. Open circles indicate potential outliers.

"torix group" which consisted of Rickettsia endosymbionts of other arthropods, e.g., Deronectes diving beetle, Rhyacophila caddisfly, Linyphia spider, Nosopsyllus flea, Anopheles mosquito, Culicoides biting midge, and other non-arthropod hosts, e.g., glossiphoniid leeches (Hemiclepsis marginata, Torix tukubana, and T. tagoi) (Figure 1). Hosts of torix clade Rickettsia are biased toward species that are either aquatic (diving beetle and caddisfly), blood feeding (bed bug and flea), or both aquatic and blood feeding (mosquito and leeches). However, the pair of loci we sequenced are not sufficient to resolve whether there is any pattern to symbiont distribution amongst host species, and analysis of this awaits a wider MLST study. The detection of a single torix Rickettsia strain in cosmopolitan bed bug species indicates that one main strain of this symbiont circulates in this species worldwide, consistent with movement alongside travelers. This finding also appears in the recent study of Potts et al. (2020). These Rickettsia strains were investigated in C. lectularius from the UK, which are independent from the populations in our study, and field collections from the USA, all of which reveal an identical gltA haplotype.

It is typical for inherited endosymbionts to be transmitted maternally between host generations (Hosokawa et al., 2010; Touret et al., 2014; Pilgrim et al., 2017; Feng et al., 2019; Rosenwald et al., 2020; Thongprem et al., 2020b). Similarly, our bed bug associated torix Rickettsia was observed to be maternally inherited. In the present experiments, maternal inheritance reliably occurred with all 310 tested offspring carrying the Rickettsia. However, evidence of segregation was observed in population F4 over the last 10-12 years of laboratory passage. Rickettsia infection in the F4 bed bug DNA materials from Duron et al. (2008) was complete, but was found in just 35\% of individuals in 2019 (ca. 100 bug generations later). Thus, whilst transmission fidelity is high, there is a low level of loss during maternal inheritance. Thus, we can conclude that whilst vertical transmission through females is very high, it does not occur with a $100 \%$ efficiency.

In contrast, no paternal transmission was observed in this study, despite paternal males carrying infections, and previous evidence of Rickettsia in male sperm vesicles (Bellinvia et al., 2020). The situation contrasts with the leafhopperassociated Rickettsia. In Nephotettix cincticeps, torix Rickettsia can transmit biparentally, with $70 \%$ paternal and $100 \%$ maternal transmission rates. The Rickettsia are found in sperm without interrupting sperm function (Watanabe et al., 2014). Paternal inheritance has also been noted for symbionts in the genus Megaira, the sister taxa to Rickettsia (Kochert and Olson, 1970). Notably, the Rickettsia in the leafhopper has the capacity for intranuclear infection, which likely is necessary for paternal inheritance. Beside this, paternal transmission is also observed in a tsetse fly-associated Sodalis symbiont (De Vooght et al., 

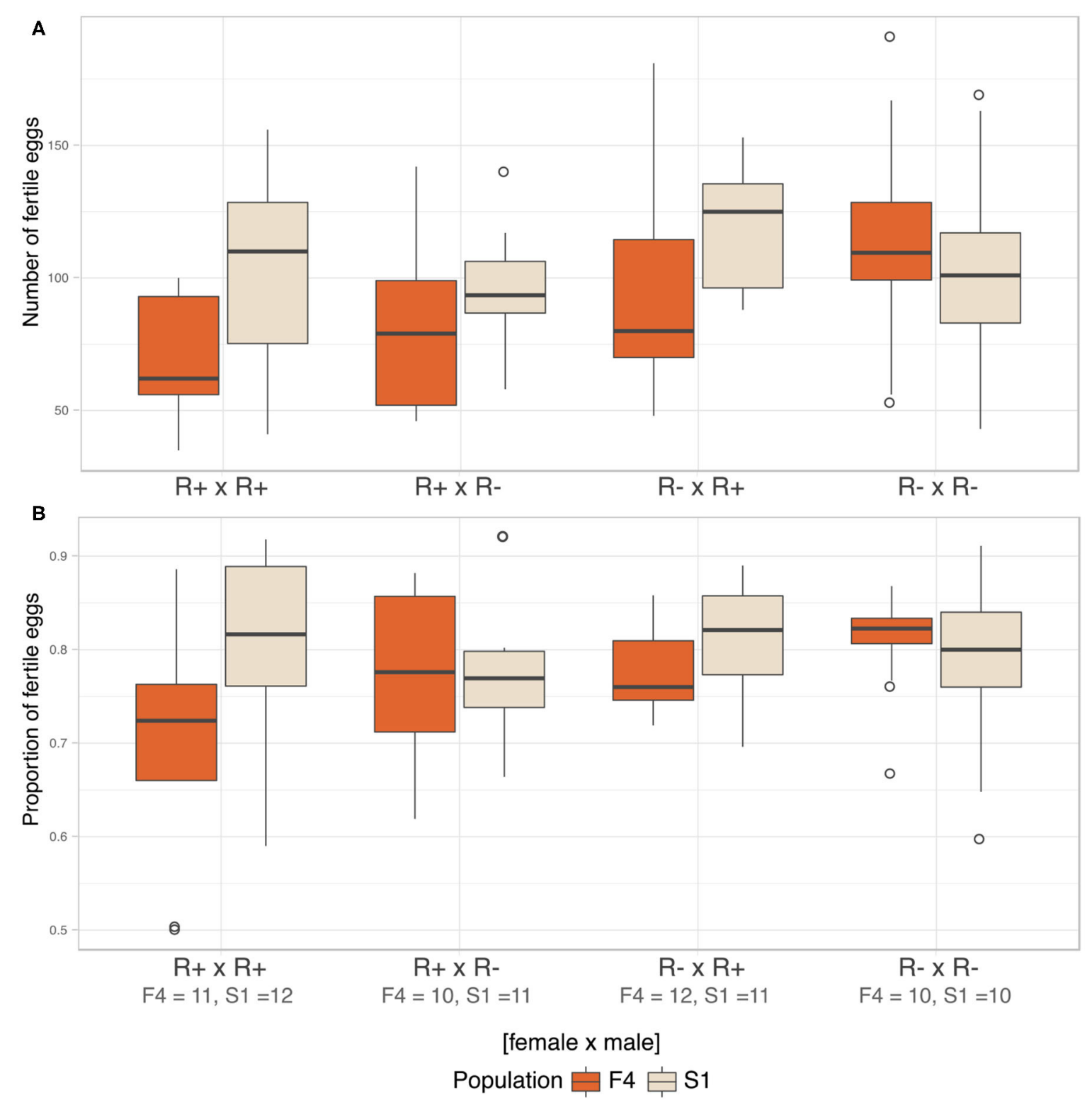

FIGURE 7 | Fecundity and $\mathrm{Cl}$. (A) Median number of fertile eggs of $C$. lectularius from population F4 and S1 from the four cross combinations. Rickettsia-infected female crosses ( $R+\times R+$ and $R+\times R-)$ produced significantly fewer fertile eggs when compare to other crosses (LRT: $\left.\chi^{2}(1)=4.576, p=0.032\right)$. (B) Median proportion of fertile eggs of $C$. lectularius from the two populations. There was no interaction effect of male and female infections on the ratio of fertile:infertile eggs from the GLMMs analysis at $p=0.05$, indicating there was no evidence of $\mathrm{Cl}$. Number of crosses completed are shown under the cross group. Boxes indicate the 25 and 75 percent quartiles, respectively, the whiskers show minimum and maximum values. Open circles indicate potential outliers.

2015). Intranuclear infection is present in several endosymbiotic bacteria, e.g., Nucleococcus, Chlamydia, gamma and alpha proteobacteria (Schulz and Horn, 2015). This trait is observed quite widely in the Rickettsiacae, but is labile, being present in some symbioses but not others (Schulz and Horn, 2015).

Insects commonly live mutualistically with endosymbionts. In many cases, insect hosts provide a pair of bacteriomes as organs for harboring their endosymbionts (Douglas, 1989; Baumann et al., 2006; Hosokawa et al., 2010; Noda et al., 2012; Marubayashi et al., 2014). Previous histological studies have located the bacteriome organs at either side of the bed bug abdomen. So far, only two bacteriome-associated endosymbionts have been described in C. lectularius, i.e., the primary endosymbiont Wolbachia and a secondary BEV-like symbiont (Hosokawa et al., 2010). Here we additionally examined the tropism of Rickettsia, alongside Wolbachia and the BEV-like symbiont. Overall, the bacteriome FISH image indicates a high signal intensity for Wolbachia. Rickettsia was also present in the bacteriome and 
the three symbionts were spatially intermixed (Figure 4D). This result contrasts with the localization of the symbiont community in the leafhopper $N$. cincticeps, in which the different symbiont species live separately. The facultative Rickettsia is widely dispersed through $N$. cincticeps bacteriomes and can be found in most of the leafhopper tissues (Mitsuhashi and Kono, 1975). When the symbiont infection has a specific territory within the bacteriome this implies a more specific function of those symbionts for their host (Nakabachi et al., 2013; Dan et al., 2017). Investigating inside the bed bug bacteriomes might help to understand the distribution of these three endosymbionts and could potentially anticipate the biological impacts of these endosymbionts on the host or their interaction.

The presence of Rickettsia in bacteriocytes indicates a route for achieving maternal inheritance. In this symbiosis, vertical transmission of Wolbachia is associated with the movement of bacteriocytes toward the ovary, where they fuse with oocytes to deliver the symbiont. The presence of Rickettsia in the bacteriome likely allows this symbiont to hitch-hike to the ovary to gain vertical transmission. However, having established in the ovary, Rickettsia and Wolbachia show distinct patterning, with Wolbachia clustering in discrete clumps and Rickettsia being more dispersed. Although this study lacks a visual evidence of Rickettsia infection in other somatic tissues (e.g., haemolymph, excretory, digestive, and immune systems), the consistent detection of Rickettsia infection in head and leg materials during the transmission experiment indicate the infection is diffusely present. Rickettsia infection in legs is likely to be derived from haemolymph, as has been reported in other Rickettsia-host systems (Hurst et al., 1996; Caspi-Fluger et al., 2011; Shan et al., 2020).

We also examined the impact of Rickettsia on bed bug biology. We found no evidence of reproductive parasitic phenotypes (sex ratio distortion or cytoplasmic incompatibility). There was evidence of a weak negative impact on first instar-adult development time, and also reduced fecundity of Rickettsia infected females. Rickettsia impact differed between the two populations tested. This may be a product of differences in symbiont or host genomes, or an interaction between the two. Overall, all metrics that we examined showed either no evidence of an effect of Rickettsia on the trait, or a deleterious impact. The results are similar to those observed in the SpalangiaRickettsia interaction, where Rickettsia (again in the presence of Wolbachia) was associated with a 1 day developmental delay, but did not induce changes in either sex ratio or CI (Semiatizki et al., 2020).

The combination of segregational loss and modest costs indicate maintenance of the symbiont in field populations will require some balancing benefit. A recent example of the biological impact of torix Rickettsia can be found in glossiphoniid leeches-associated Rickettsia. The case study demonstrates that Rickettsia have a direct effect on the body size of the three leech host species, with infected individuals being larger (Kikuchi and Fukatsu, 2005). A recent study has examined the genome sequence of torix Rickettsia endosymbiont of Culicoides newsteadi, a strain closely related to bed bugassociated Rickettsia (Pilgrim et al., 2017). No evidence of the capacity for positive facilitation was observed in the genome, e.g., B-vitamin provisioning. However, the genome possesses unique features of genes that are potentially associated with host invasion and adaptation (Pilgrim et al., 2017). It is likely that any benefits of Rickettsia infection are ecologically contingent, and parallel with other symbioses indicating resistance to environmental stress or pathogen susceptibility as worthwhile avenues for research.

\section{DATA AVAILABILITY STATEMENT}

The datasets presented in this study can be found in online repositories. The names of the repository/repositories and accession number(s) can be found in the article/Supplementary Material.

\section{AUTHOR CONTRIBUTIONS}

The study was initially devised by PT and GH and experiments designed by PT, SE, GH, and OO. Rearing of bed bugs was completed by SE and OO. Screening of bed bugs, marker sequencing, and FISH analysis was completed by PT with advice from GH. Analysis of developmental time, sex ratio, fecundity, and incompatibility were completed by OO. PT, OO, and $\mathrm{GH}$ wrote the manuscript and all authors contributed to the drafting.

\section{FUNDING}

The project was supported by the Development and Promotion of Science and Technology Talents Project (DPST) of the Institute for the Promotion of Teaching Science and Technology, Thailand to PT. OO was supported by a grant from the German Research Foundation DFG (OT 521/2-1). Microscopy was conducted at the Centre for Cell Imaging (CCI), using equipment funded from BBSRC grant BB/M012441/1.

\section{ACKNOWLEDGMENTS}

We are grateful to Steffen Roth (University Museum of Bergen) and Klaus Reinhardt (TU Dresden) who made samples available from their recently published phylogeny (Roth et al., 2019). Thanks to Sam Edwards for bed bug instars in FISH imaging. This manuscript has been released as a pre-print at BioRxiv (Thongprem et al., 2020b).

\section{SUPPLEMENTARY MATERIAL}

The Supplementary Material for this article can be found online at: https://www.frontiersin.org/articles/10.3389/fmicb. 2020.608763/full\#supplementary-material 


\section{REFERENCES}

Azad, A. F., and Beard, C. B. (1998). Rickettsial pathogens and their arthropod vectors. Emerging Infect. Dis. 4, 179-186. doi: 10.3201/eid0402.980205

Bates, D., Mächler, M., Bolker, B., and Walker, S. (2015). Fitting linear mixedeffects models using lme4. J. Stat. Softw. 67, 1-48. doi: 10.18637/jss.v067.i01

Baumann, P., Moran, N. A., and Baumann, L. (2006). "Bacteriocyte-associated endosymbionts of insects," in The Prokaryotes: Volume 1: Symbiotic Associations, Biotechnology, Applied Microbiology, eds M. Dworkin, S. Falkow, E. Rosenberg, K.-H. Schleifer, and E. Stackebrandt (New York, NY: Springer New York), 403-438. doi: 10.1007/0-387-30741-9_16

Bellinvia, S., Johnston, P. R., Reinhardt, K., and Otti, O. (2020). Bacterial communities of the reproductive organs of virgin and mated common bedbugs, Cimex lectularius. Ecol. Entomol. 45, 142-154. doi: 10.1111/een.12784

Caspi-Fluger, A., Inbar, M., Mozes-Daube, N., Mouton, L., Hunter, M. S., and Zchori-Fein, E. (2011). Rickettsia 'In' and 'Out': two different localization patterns of a bacterial symbiont in the same insect species. PLoS ONE 6:e21096. doi: 10.1371/journal.pone.0021096

Dan, H., Ikeda, N., Fujikami, M., and Nakabachi, A. (2017). Behavior of bacteriome symbionts during transovarial transmission and development of the Asian citrus psyllid. PLOS ONE 12:e0189779. doi: 10.1371/journal.pone.0189779

Davis, N. T. (1956). The morphology and functional anatomy of the male and female reproductive systems of Cimex Lectularius L. (Heteroptera, Cimicidae). Ann. Entomol. Soc. Am. 49, 466-493. doi: 10.1093/aesa/49.5.466

De Vooght, L., Caljon, G., Van Hees, J., and Van Den Abbeele, J. (2015). Paternal transmission of a secondary symbiont during mating in the viviparous tsetse fly. Mol. Biol. Evol. 32, 1977-1980. doi: 10.1093/molbev/msv077

Degnan, P. H., Bittleston, L. S., Hansen, A. K., Sabree, Z. L., Moran, N. A., Almeida, R. P. (2011). Origin and examination of a leafhopper facultative endosymbiont. Curr. Microbiol. 62, 1565-1572. doi: 10.1007/s00284-011-9893-5

Douglas, A. E. (1989). Mycetocyte symbiosis in insects. Biol. Rev. 64, 409-434. doi: 10.1111/j.1469-185X.1989.tb00682.x

Duron, O., Bouchon, D., Boutin, S., Bellamy, L., Zhou, L., Engelstädter, J., et al. (2008). The diversity of reproductive parasites among arthropods: Wolbachia do not walk alone. BMC Biol. 6:27. doi: 10.1186/1741-7007-6-27

Feng, H., Edwards, N., Anderson, C. M. H., Althaus, M., Duncan, R. P., Hsu, Y.-C., et al. (2019). Trading amino acids at the aphid-Buchnera symbiotic interface. Proc. Nat. Acad. Sci. U.S.A. 116:16003. doi: 10.1073/pnas.1906223116

Folmer, O., Black, M., Hoeh, W., Lutz, R., and Vrijenhoek, R. (1994). DNA primers for amplification of mitochondrial cytochrome c oxidase subunit I from diverse metazoan invertebrates. Mol. Marine Biol. Biotechnol. 3, 294-299.

Gaon, J. A., and Murray, E. S. (1966). The natural history of recrudescent typhus (Brill-Zinsser disease) in Bosnia. Bull. World Health Organ. 35, 133-141. doi: 10.1016/B978-1-4832-2913-3.50343-9

Giorgini, M., Bernardo, U., Monti, M. M., Nappo, A. G., and Gebiola, M. (2010). Rickettsia symbionts cause parthenogenetic reproduction in the parasitoid wasp Pnigalio soemius (Hymenoptera: Eulophidae). Appl. Environ. Microbiol. 76, 2589-2599. doi: 10.1128/AEM.03154-09

Goodacre, S. L., Martin, O. Y., Thomas, C. F., and Hewitt, G. M. (2006). Wolbachia and other endosymbiont infections in spiders. Mol. Ecol. 15, 517-527. doi: 10.1111/j.1365-294X.2005.02802.x

Gotoh, T., Noda, H., and Ito, S. (2007). Cardinium symbionts cause cytoplasmic incompatibility in spider mites. Heredity 98, 13-20. doi: 10.1038/sj.hdy.6800881

Gross, L. (1996). How Charles Nicolle of the Pasteur Institute discovered that epidemic typhus is transmitted by lice: reminiscences from my years at the Pasteur Institute in Paris. Proc. Natl. Acad. Sci. U.S.A. 93, 10539-10540. doi: 10.1073/pnas.93.20.10539

Hendry, T. A., Hunter, M. S., and Baltrus, D. A. (2014). The facultative symbiont Rickettsia protects an invasive whitefly against entomopathogenic Pseudomonas syringae strains. Appl. Environ. Microbiol. 80, 7161-7168. doi: 10.1128/AEM.02447-14

Hosokawa, T., Koga, R., Kikuchi, Y., Meng, X.-Y., and Fukatsu, T. (2010). Wolbachia as a bacteriocyte-associated nutritional mutualist. PNAS 107, 769-774. doi: 10.1073/pnas.0911476107

Hurst, G. D. D., and Frost, C. L. (2015). Reproductive parasitism: maternally inherited symbionts in a biparental world. Cold Spring Harb. Perspect. Biol. 7:a017699. doi: 10.1101/cshperspect.a017699
Hurst, G. D. D., Walker, L. E., and Majerus, M. E. N. (1996). Bacterial infections of hemocytes associated with the maternally inherited male-killing trait in british populations of the two spot ladybird, Adalia bipunctata. J. Invertebr. Pathol. 68, 286-292. doi: 10.1006/jipa.1996.0098

Hwang, S. W., Svoboda, T. J., De Jong, I. J., Kabasele, K. J., and Gogosis, E. (2005). Bed bug infestations in an urban environment. Emerging Infect. Dis. 11, 533-538. doi: 10.3201/eid1104.041126

Kikuchi, Y., and Fukatsu, T. (2005). Rickettsia infection in natural leech populations. Microb. Ecol. 49, 265-271. doi: 10.1007/s00248-004-0140-5

Kikuchi, Y., Sameshima, S., Kitade, O., Kojima, J., and Fukatsu, T. (2002). Novel clade of Rickettsia spp. from leeches. Appl. Environ. Microbiol. 68, 999-1004. doi: 10.1128/AEM.68.2.999-1004.2002

Kochert, G., and Olson, L. W. (1970). Endosymbiotic bacteria in Volvox carteri. Trans. Am. Microsc. Soc. 89, 475-478. doi: 10.2307/3224556

Küchler, S. M., Kehl, S., and Dettner, K. (2009). Characterization and localization of Rickettsia sp. in water beetles of genus Deronectes (Coleoptera: Dytiscidae). FEMS Microbiol. Ecol. 68, 201-211. doi: 10.1111/j.1574-6941.2009.00665.x

Kumar, S., Stecher, G., Li, M., Knyaz, C., and Tamura, K. (2018). MEGA X: Molecular evolutionary genetics analysis across computing platforms. Mol. Biol. Evol. 35, 1547-1549. doi: 10.1093/molbev/msy096

Marubayashi, J. M., Kliot, A., Yuki, V. A., Rezende, J. A. M., Krause-Sakate, R., Pavan, M. A., et al. (2014). Diversity and localization of bacterial endosymbionts from whitefly species collected in Brazil. PLoS ONE 9:e108363. doi: 10.1371/journal.pone. 0108363

Meriweather, M., Matthews, S., Rio, R., and Baucom, R. S. (2013). A 454 survey reveals the community composition and core microbiome of the common bed bug (Cimex lectularius) across an urban landscape. PLoS ONE 8:e61465. doi: 10.1371/journal.pone.0061465

Mitsuhashi, J., and Kono, Y. (1975). Intracellular microorganisms in the green rice leafhopper, Nephotettix cincticeps UHLER (Hemiptera: Deltocephalidae). Appl. Entomol. Zool. 10, 1-9. doi: 10.1303/aez.10.1

Mitter, C., Farrell, B., and Wiegmann, B. (1988). The phylogenetic study of adaptive zones: has phytophagy promoted insect diversification? Am. Nat. 132, 107-128. doi: $10.1086 / 284840$

Nakabachi, A., Ueoka, R., Oshima, K., Teta, R., Mangoni, A., Gurgui, M., et al. (2013). Defensive bacteriome symbiont with a drastically reduced genome. Curr. Biol. 23, 1478-1484. doi: 10.1016/j.cub.2013.06.027

Noda, H., Watanabe, K., Kawai, S., Yukuhiro, F., Miyoshi, T., Tomizawa, M., et al. (2012). Bacteriome-associated endosymbionts of the green rice leafhopper Nephotettix cincticeps (Hemiptera: Cicadellidae). Appl. Entomol. Zool. 47, 217-225. doi: 10.1007/s13355-012-0110-1

Okonechnikov, K., Golosova, O., and Fursov, M., the Ut. (2012). Unipro UGENE: a unified bioinformatics toolkit. Bioinformatics 28, 1166-1167. doi: 10.1093/bioinformatics/bts091

Park, E., and Poulin, R. (2020). Widespread torix Rickettsia in New Zealand amphipods and the use of blocking primers to rescue host COI sequences. Sci. Rep. 10:16842. doi: 10.1038/s41598-020-73986-1

Perotti, M. A., Clarke, H. K., Turner, B. D., and Braig, H. R. (2006). Rickettsia as obligate and mycetomic bacteria. FASEB J. 20, 1646-1656. doi: 10.1096/fj.06-5870fje

Pilgrim, J., Ander, M., Garros, C., Baylis, M., Hurst, G. D. D., and Siozios, S. (2017). Torix group Rickettsia are widespread in Culicoides biting midges (Diptera: Ceratopogonidae), reach high frequency and carry unique genomic features. Environ. Microbiol. 19, 4238-4255. doi: 10.1111/1462-2920.13887

Potts, R., Molina, I., Sheele, J. M., and Pietri, J. E. (2020). Molecular detection of Rickettsia infection in field-collected bed bugs. New Microb. New Infect. 34:100646. doi: 10.1016/j.nmni.2019.100646

R Development Core Team (2019). R: A Language and Environment for Statistical Computing. Vienna: R Foundation for Statistical Computing. Available online at: http://www.R-project.org (accessed October 24, 2019).

Reinhardt, K., Naylor, R., and Siva-Jothy, M. T. (2003). Reducing a cost of traumatic insemination: female bedbugs evolve a unique organ. Proc. $R$. Soc. London Ser. B 270, 2371-2375. doi: 10.1098/rspb.2003.2515

Reinhardt, K., Naylor, R. A., and Siva-Jothy, M. T. (2009b). Ejaculate components delay reproductive senescence while elevating female reproductive rate in an insect. Proc. Nat. Acad. Sci. 106:21743. doi: 10.1073/pnas.0905 347106 
Reinhardt, K., Naylor, R. A., and Siva-jothy, M. T. (eds). (2009a). Situation exploitation: higher male mating success when female resistance is reduced by feeding. Evolution 63, 29-39. doi: 10.1111/j.1558-5646.2008.00502.x

Ribeiro, J. M. C., and Valenzuela, J. G. (2011). "Chapter 8 - vector biology," in Tropical Infectious Diseases: Principles, Pathogens and Practice, $3 r d$ Edn, eds R. L. Guerrant, D. H. Walker, and P. F. Weller (Edinburgh: W.B. Saunders), 45-51. doi: 10.1016/B978-0-7020-3935-5.00008-2

Rosenwald, L. C., Sitvarin, M. I., and White, J. A. (2020). Endosymbiotic Rickettsiella causes cytoplasmic incompatibility in a spider host. Proc. R. Soc. B Biol. Sci. 287:20201107. doi: 10.1098/rspb.2020.1107

Roth, S., Balvín, O., Siva-Jothy, M. T., Di Iorio, O., Benda, P., Calva, O., et al. (2019). Bedbugs evolved before their bat hosts and did not co-speciate with ancient humans. Curr. Biol. 29, 1847-1853. doi: 10.1016/j.cub.2019.04.048

Sakamoto, J. M., and Rasgon, J. L. (2006). Geographic distribution of Wolbachia infections in Cimex lectularius (Heteroptera: Cimicidae). J. Med. Entomol. 43, 696-700. doi: 10.1093/jmedent,/43.4.696

Sakurai, M., Koga, R., Tsuchida, T., Meng, X.-Y., and Fukatsu, T. (2005). Rickettsia symbiont in the pea aphid Acyrthosiphon pisum: novel cellular tropism, effect on host fitness, and interaction with the essential symbiont Buchnera. Appl. Environ. Microbiol. 71, 4069-4075. doi: 10.1128/AEM.71.7.4069-4075.2005

Schulz, F., and Horn, M. (2015). Intranuclear bacteria: inside the cellular control center of eukaryotes. Trends Cell Biol. 25, 339-346. doi: 10.1016/j.tcb.2015.01.002

Semiatizki, A., Weiss, B., Bagim, S., Rohkin-Shalom, S., Kaltenpoth, M., and Chiel, E. (2020). Effects, interactions, and localization of Rickettsia and Wolbachia in the house fly parasitoid, Spalangia endius. Microb. Ecol. 80, 718-728. doi: 10.1007/s00248-020-01520-x

Shan, H., Liu, Y., Luan, J., and Liu, S. (2020). New insights into the transovarial transmission of the symbiont Rickettsia in whiteflies. Sci. China Life Sci. doi: 10.1007/s11427-020-1801-7. [Epub ahead of print].

Simon, C., Frati, F., Beckenbach, A., Crespi, B., Liu, H., and Flook, P. (1994). Evolution, weighting, and phylogenetic utility of mitochondrial gene sequences and a compilation of conserved polymerase chain reaction primers. Ann. Entomol. Soc. Am. 87, 651-701. doi: 10.1093/aesa/87.6.651

Siva-Jothy, M. T., and Stutt, A. D. (2003). A matter of taste: direct detection of female mating status in the bedbug. Proc. R. Soc. London Ser. B Biol. Sci. 270, 649-652. doi: 10.1098/rspb.2002.2260

Song, S., Chen, C., Yang, M., Zhao, S., Wang, B., Hornok, S., et al. (2018). Diversity of Rickettsia species in border regions of northwestern China. Parasites Vectors 11:634. doi: 10.1186/s13071-018-3233-6

Stecher, G., Tamura, K., and Kumar, S. (2020). Molecular evolutionary genetics analysis (MEGA) for macOS. Mol. Biol. Evol. 37, 1237-1239 doi: $10.1093 / \mathrm{molbev} / \mathrm{msz} 312$

Sudakaran, S., Kost, C., and Kaltenpoth, M. (2017). Symbiont acquisition and replacement as a source of ecological innovation.
Trends Microbiol. 25, 375-390. doi: 10.1016/j.tim.2017. 02.014

Thongprem, P., Davison, H. R., Thompson, D. J., Lorenzo-Carballa, M. O., and Hurst, G. D. D. (2020a). Incidence and diversity of torix Rickettsiaodonata symbioses. Microb. Ecol. doi: 10.1007/s00248-020-01568-9. [Epub ahead of print].

Thongprem, P., Evison, S. E. F., Hurst, G. D. D., and Otti, O. (2020b). Transmission, tropism and biological impacts of torix Rickettsia in the common bed bug Cimex lectularius (Hemiptera: Cimicidae). bioRxiv [Preprint]. 2020.09.20.305367. doi: 10.1101/2020.09.20.305367

Touret, F., Guiguen, F., and Terzian, C. (2014). Wolbachia influences the maternal transmission of the gypsy endogenous retrovirus in Drosophila melanogaster. MBio 5:e01529. doi: 10.1128/mBio.01529-14

Usinger, R. L. (1966). Monograph of Cimicidae (Hemiptera, Heteroptera). The Thomas Say Foundation, College Park, MD: Entomological Society of America, 585.

Wang, H.-L., Lei, T., Wang, X.-W., Maruthi, M. N., Zhu, D.-T., Cameron, S. L., et al. (2020). A newly recorded Rickettsia of the Torix group is a recent intruder and an endosymbiont in the whitefly Bemisia tabaci. Environ. Microbiol. 22, 1207-1221. doi: 10.1111/1462-2920.14927

Watanabe, K., Yukuhiro, F., Matsuura, Y., Fukatsu, T., and Noda, H. (2014). Intrasperm vertical symbiont transmission. PNAS 111, 7433-7437. doi: $10.1073 /$ pnas.1402476111

Werren, J. H. (2012). Symbionts provide pesticide detoxification. Proc. Nat. Acad. Sci. 109:8364. doi: 10.1073/pnas.1206194109

Werren, J. H., Hurst, G. D., Zhang, W., Breeuwer, J. A., Stouthamer, R., and Majerus, M. E. (1994). Rickettsial relative associated with male killing in the ladybird beetle (Adalia bipunctata). J. Bacteriol. 176, 388-394. doi: 10.1128/JB.176.2.388-394.1994

Zabalou, S., Riegler, M., Theodorakopoulou, M., Stauffer, C., Savakis, C., and Bourtzis, K. (2004). Wolbachia induced cytoplasmic incompatibility as a means for insect pest population control. Proc. Natl. Acad. Sci. U.S.A. 101:15042. doi: 10.1073/pnas.0403853101

Conflict of Interest: The authors declare that the research was conducted in the absence of any commercial or financial relationships that could be construed as a potential conflict of interest.

Copyright (C) 2020 Thongprem, Evison, Hurst and Otti. This is an open-access article distributed under the terms of the Creative Commons Attribution License (CC BY). The use, distribution or reproduction in other forums is permitted, provided the original author(s) and the copyright owner(s) are credited and that the original publication in this journal is cited, in accordance with accepted academic practice. No use, distribution or reproduction is permitted which does not comply with these terms. 